\title{
Decisive and timely management - A case of fatal acute decompensated cardiomyopathy at 35 weeks of pregnancy
}

\author{
Abhishek Madankumar Deshpande ${ }^{I^{*}}$, Meera Santosh ${ }^{2}$ \\ Senior Resident ${ }^{1 *}$, ConsultantAnaesthetist ${ }^{2}$ Global Hospital super-specialty and Transplant centre \\ Mumbai 400012, India.
}

\begin{abstract}
Peripartum cardiomyopathy (PPCM) is a relatively rare disease occurring most commonly in the postpartum period. A small subset of patients with PPCM present at later stages of pregnancies. The management of PPCM involves guideline-based treatment of cardiac failure. There is a paucity of data regarding timing of delivery and final outcome. Patients presenting with decompensated failure or progressively worsening symptoms need emergent termination of pregnancy along with stabilisation. We present a 35-week pregnant patient in cardiac failure in whom early delivery and effective postoperative management resulted in a favourable outcome for both mother and child.
\end{abstract}

Keywords: Peripartum cardiomyopathy; early delivery; pregnancy

\section{Introduction}

Peripartum cardiomyopathy (PPCM) is a relatively rare and fatal disease occurring late in pregnancy or in the postpartum period. Though the exact incidence in India is unknown, 1 in 1000 to 4000 women in the USA are diagnosed with PPCM. ${ }^{1}$ PPCM requires a high index of suspicion as milder symptoms mimic normal pregnancy. Presentation of the disease varies, with common symptom being NYHA class III or IV dyspnoea and rarely arrythmias and even

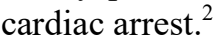

\section{Case History}

A $42 \mathrm{yr}$ old lady $\mathrm{G}_{2} \mathrm{P}_{1} \mathrm{~L}_{1}$ with $35+4$ weeks of gestation presented to the emergency with sudden onset breathlessness. On arrival, she was tachypnoeic with a blood pressure of $160 / 100 \mathrm{mmHg}$, pulse $110 / \mathrm{min}$ and saturation of $75 \%$. She was hypoxaemic with disorientation and inability to obey commands. History taken from the relatives revealed that they had immediately reached the hospital upon developing symptoms and she had no previous cardiac symptoms. She was on labetolol and thyroid supplement for pregnancy induced hypertension and hypothyroidism respectively. Differential diagnoses at this point were pulmonary oedema secondary to
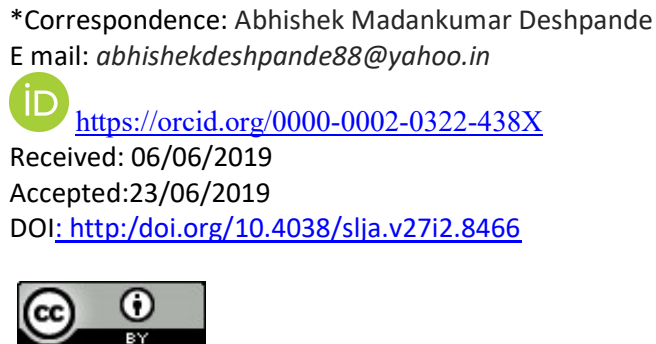

cardiomyopathy, severe pre-eclampsia with pulmonary oedema, amniotic fluid embolism or thromboembolism. It was then decided to secure the airway and deliver the baby immediately. The patient was shifted to the operating room to reduce time to delivery and to induce the patient in a controlled environment.

In the operating room, rapid sequence induction was performed for intubation. The airway pressure after intubation was $50 \mathrm{cmH}_{2} \mathrm{O}$, endtidal $\mathrm{CO}_{2}-80 \mathrm{mmHg}$. Intravenous frusemide $20 \mathrm{mg}$ had to be repeated thrice until the airway pressures allowed us to ventilate satisfactorily. Simultaneously the obstetricians delivered the baby. Time taken from patient's arrival to hospital and baby being delivered was less than 15 minutes. Post-delivery the airway pressures reduced to $30 \mathrm{cmH}_{2} \mathrm{O}$. Remainder of the surgery was uneventful with haemodynamic stability being achieved. The patient was shifted to ICU on ventilator in view of persistent high airway pressures and poor ventilation $\left(\mathrm{pO}_{2}-87\right.$ and $\left.\mathrm{pCO}_{2}-59\right)$.

In the post-operative period screening echocardiography showed global hypokinesia with ejection fraction (EF) of $20 \%$ and chest $\mathrm{x}$ ray (Figure 1) showed bilateral interstitial oedema.

Management was started by maintaining negative fluid balance, diuretics were continued. Nitroglycerine infusion was started for blood pressure control and invasive arterial line was secured for monitoring. Ivabradine was pressure control and invasive arterial line was secured for monitoring. Ivabradine was commenced for rate 


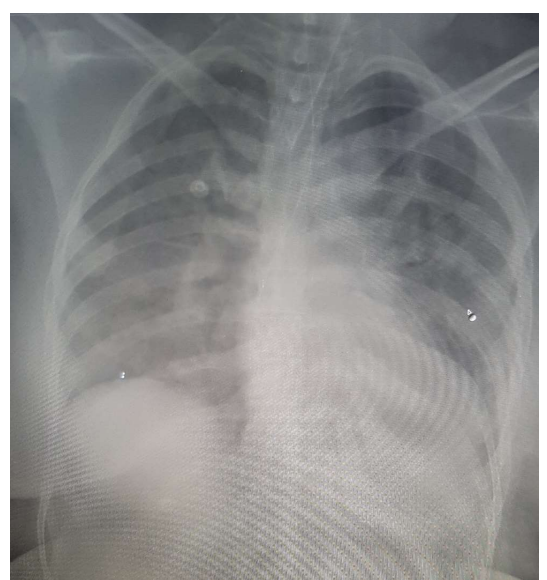

Figure 1 Chest $\mathrm{x}$ ray showing oedema

control as part of anti-failure treatment and enoxaparin was started for anticoagulation. Over a period of 24 hours intravenous vasodilators were tapered and antihypertensives (metoprolol $25 \mathrm{mg} \mathrm{BD}$, isosorbide mononitrate $10 \mathrm{mg} \mathrm{BD}$ and amlodipine $5 \mathrm{mg}$ BD) were administered through naso-gastric tube. Patients' oxygenation improved and she was extubated on the second post-operative day. Cabergoline a prolactin inhibitor and dopamine agonist for PPCM was considered but was deferred in view of improving LV function and prospect of breast feeding. There was significant clinical improvement and $\mathrm{EF}$ increased to $50 \%$ by the fourth day post-delivery. Subsequently, the patient was discharged on the fifth day with further follow up with cardiologist.

\section{Discussion}

PPCM as defined by European cardiology society is reduced EF, usually $<45 \%$ (with or without dilated LV), presenting toward the end of pregnancy or in the months after delivery in a woman without previously known structural heart disease. ${ }^{3}$ Risk factors for cardiomyopathy include cardiovascular factors (hypertension, diabetes, smoking) and pregnancy-related factors (age, multiple pregnancies, use of medication facilitating birth, malnutrition). ${ }^{4,5}$

Most women with PPCM present in the postpartum period, with a small subset in the second and third trimesters. ${ }^{5}$ Symptoms include dyspnoea, orthopnoea, paroxysmal nocturnal dyspnoea. Physical examination often reveals signs of heart failure, including tachycardia, elevated jugular venous pressure, pulmonary rales, and peripheral oedema. It can also present in decompensated state with low cardiac output needing pharmacological and mechanical support $^{1}$

PPCM related mortality varies across the world. Various factors such as genetic predisposition, socio economic status, access to health care and delay in diagnosis affect outcome. ${ }^{1}$ A recent study in South Africa with 176 patients showed $13 \%$ died and $25 \%$ had persistent LVEF $<35 \%$ at 6 months. Only $21 \%$ of the survivors had fully recovered LVEF (>55\%). ${ }^{6}$ Similarly, poor outcomes were reported in Turkey, in which 10 of 42 patients (24\%) with PPCM died, and only $30 \%$ of the patients had recovered LV function at 6 months. $^{7}$

Management of PPCM involves guideline-based treatment of heart failure but literature regarding timing of delivery of baby in a patient presenting at or before term is ambiguous. There is no literature which shows change in outcome with timing of delivery. Our patient presented to us at near term and in a decompensated state with severe respiratory distress, acidosis and disorientation. Decision to deliver the baby was decided by both obstetrician and anaesthetist to prevent fatality. However, diagnosis of PPCM which is mostly a diagnosis of exclusion was done in the postpartum period. In our case rather we opted for early delivery and concomitant stabilisation of the patient which was crucial for better outcome of the patient, the time to deliver the child from arrival to the hospital was less than 15 minutes.

Huang et $\mathrm{al}^{8}$ reported a successful outcome for patient who presented in cardiac failure at 33 weeks. However, outcome of the foetus wasn't favourable as it was still birth at presentation, the patient had developed symptoms two days prior and the outcome of the foetus could have been different if presented early.

Lata et $\mathrm{al}^{9}$ reported successful outcome for both mother and child where the patient presented at 37 weeks of gestation with sudden onset cardiac symptoms. Attempts to stabilise the patient and then deliver was done for first few hours. However, the foetus passed meconium the baby and she was delivered via an emergency caesarean section.

Kotekar et al ${ }^{10}$ reported a case of PPCM in $37 \mathrm{yr}$ old patient with 37 weeks of gestation. The 
patient did not have favourable outcome, succumbing to death on the $8^{\text {th }}$ post-operative day, however the baby survived.

The above studies show that the decision and timing to terminate the pregnancy is critical in the management of PPCM. Emergent caesarean section should be performed when the patient's condition worsens. It is our opinion that emergent delivery with simultaneous stabilisation leads to favourable outcome in decompensated patients.

\section{References}

1. ZoltArany, Uri Elkayam Peripartum Cardiomyopathy. Circulation 2016;133:13971409.

https://doi.org/10.1161/CIRCULATIONAHA.11 $\underline{5.020491}$

PMid:27045128

2. Elkayam U Clinical Characteristics of Peripartum Cardiomyopathy in the United States: Diagnosis, Prognosis, and Management. J Am Coll Cardiol. 2011;58(7):659-70. https://doi.org/10.1016/j.jacc.2011.03.047 PMid:21816300

3. Sliwa K1, Hilfiker-Kleiner D, Petrie MC, Mebazaa A, Pieske B, Buchmann E et al, Current state of knowledge on aetiology, diagnosis, management, and therapy of peripartum cardiomyopathy: a position statement from the Heart Failure Association of the European Society of Cardiology Working Group on peripartum cardiomyopathy. Eur J Heart Fail. 2010;12(8):767-78.

https://doi.org/10.1093/eurihf/hfq120

PMid:20675664

4. Sliwa K1, Fett J, Elkayam U. Peripartum cardiomyopathy. Lancet. 2006 19;368(9536):687-93.

https://doi.org/10.1016/S0140-6736(06)69253-2

5. Uri Elkayam, Mohammed W. Akhter, Harpreet Singh, Salman Khan, FahedBitar, Afshan Hameed et al. Pregnancy-Associated Cardiomyopathy Clinical Characteristics and a Comparison Between Early and Late Presentation. Circulation 2005; 111:2050-2055 https://doi.org/10.1161/01.CIR.0000162478.366 $\underline{52.7 \mathrm{E}}$

PMid: 15851613

6. Blauwet LA, Libhaber E, Forster $\mathrm{O}$ et al. Predictors of outcome in 176 South African patients with peripartum cardiomyopathy. Heart. 2013; 99:308-313 https://doi.org/10.1136/heartjnl-2012-302760 PMid:23118348

7. Biteker M, Ilhan E, Biteker G, Duman D, Bozkurt B. Delayed recovery in peripartum cardiomyopathy: an indication for long-term follow-up and sustained therapy. Eur J Heart Fail. 2012; 14:895-901

https://doi.org/10.1093/eurjhf/hfs070 PMid:22588321

8. Huang Yaqing, Chen Tianqi, Zhang Meiqi et al. Successful management of fatal peripartum cardiomyopathy in a young pregnant woman. Medicine: 2018; 97(15):0408

https://doi.org/10.1097/MD.0000000000010408 PMid:29642207 PMCid:PMC5908600

9. Indu Lata, Renu Gupta, Sandeep Sahu, and Harpreet Singh. Emergency management of decompensated peripartum cardiomyopathy. J Emerg Trauma Shock 2009; 2(2): 124-128. https://doi.org/10.4103/0974-2700.50748 PMid:19561973 PMCid:PMC2700591

10. Nalini Kotekar, NV Nagalakshmi, Chandrashekar. A rare case of peripartum cardiomyopathy posted for caesarean section. Indian journal of anaesthesia 2007; 51(1):60-64 https://doi.org/10.4103/ija.IJA 76918 PMid:31000900 PMCid:PMC6460981 